How to cite

Awang-Hashim, R., Kaur, A., \& Valdez, N. P. (2019). Strategizing inclusivity in teaching diverse learners in higher education. Malaysian Journal of Learning and Instruction, 16(1), 105-128.

\title{
STRATEGIZING INCLUSIVITY IN TEACHING DIVERSE LEARNERS IN HIGHER EDUCATION
}

\author{
${ }^{1}$ Rosna Awang-Hashim, ${ }^{2}$ Amrita Kaur \& ${ }^{3}$ Nena P.Valdez \\ ${ }^{1 \& 2}$ School of Education and Modern Languages \\ Universiti Utara Malaysia, Malaysia \\ ${ }^{3}$ President University, Indonesia \\ ${ }^{2}$ Corresponding author: amrita@uum.edu.my
}

Received: 23 February 2018 Revised: 6 December 2018 Accepted: 2 January 2019

\begin{abstract}
Purpose - As the classrooms in higher education are growing increasingly diverse, it is imperative that higher education practitioners build a responsive learning environment for diverse learners to optimize their potential. Continuing professional development programmes (CPD) are central to such strategic approaches that equip educators with essential knowledge and skills to handle diversity related issues, achieve equity and increase student participation. Therefore, the present study aims to examine strategies used by higher education practitioners to address diversity and inclusion in teaching and learning.
\end{abstract}

Methodology - Participants comprised nine academicians (six men and three women) who emerged from natural retention along the iterative cycles on community of practice (CoP) participation. This study adopted $\mathrm{CoP}$ as the theoretical lens and methodological tool to understand the strategies higher education practitioners have devised for their inclusive teaching and learning practices in response to diversity related challenges. The data was collected through a series of observations and reflective journals. Initially, thematic analysis 
techniques were used to reduce data into two categories - strategies and challenges. Later, according to prevalence and frequency counts, the strategies were analysed against the challenges reported and finally the strategies were reduced to major themes.

Findings - Three major themes emerged which reported on the inclusive strategies conceived by the participants. The themes were inclusive/differentiated assessment which suggested that creating differentiated assessment that were inclusive in nature could provide equal opportunities for each and every student to participate. The second theme, motivation and goal strategies revealed that students were diverse in their goals for learning. Hence, a variety of motivational strategies such as including students' voice, providing them with a clear rationale for studying and fostering relatedness were deemed suitable to address these differences. The final theme, inclusive pedagogy suggested a variety of accommodation to be made in pedagogy such as integrating technology, adopting culturally responsive material and initiating collaborative learning to address students' differences.

Significance - The findings have implications for faculty professional development, classroom teaching practices employing inclusive pedagogy in higher education institutions and the use of $\mathrm{CoP}$ as a framework for such developments.

Keywords: Diversity, higher education, teaching and learning, CoP, inclusion.

\section{INTRODUCTION}

The wide array of forces that shape the nature of a contemporary higher education classroom ranges from globalization to technological advancements to economic and social transformations. These trends, in turn contribute to the diversity among students in terms of their personality, identity and world view. Furthermore, students from varied geographic locations, religion, cultures, ethnicities, languages, educational backgrounds, socio-economic status and work experience contribute toward a more complex classroom landscape (De Wit, 2011; Kaur, Awang-Hashim, \& Noman, 2017). These demographics and relentless expectations of the globalized 
economy require higher education practitioners to re-examine and realign their teaching and learning practices. It is essential that classroom practices, design, and ecosystem ensure participation and equal opportunities for all students regardless of physical, cognitive, affective and conative differences (Gale \& Mills, 2013; Kift, Nelson, \& Clarke, 2010).

The ability to embed inclusivity in teaching and learning approaches is one potential way forward to acknowledge and address the complexities of existing classrooms in higher education (Barrington, 2004). Student diversity is a multifaceted phenomenon; however, the goal is singular and specific which suggests that through our practices we should overcome the barriers to participation and facilitate increased participation of every member in the class (Ainscow, 1999). Consequently, it is important that higher education practitioners participate in strategic reflection to review and understand how diversity and inclusion is conceptualized and managed in their own context.

Continuing professional development (CPD) is central to such strategic approaches that equip educators with essential knowledge and skills to handle diversity related issues, achieve equity and increase student participation (May \& Bridger, 2010). More than a decade ago Schneider (2000) had reported that $60 \%$ of colleges and universities in the United States were involved in some form of diversity related initiatives. This suggests that currently the majority of higher education institutions around the world have most likely undergone a process of systematic review and revisions for diversity initiatives. However, given the multifaceted nature of diversity related issues and solutions, it is imperative that each institution investigates and designs diversity initiatives according to its local context. For example, May and Bridger (2010) in a comprehensive study reported a case study of 10 institutions across the United Kingdom on inclusive policy and practice considering there were variations between institutions and their diversity initiatives. According to them, "Institutions chose methods that fitted their context and, while teams had methods in common, no two teams were found to use the same overall approach, even though they may have been targeting the same issue" (p. 4).

Considering the fact that context is central to strategizing diversity initiatives, the present study initiated a Community of Practice 
(CoP) of higher education practitioners in a public university to achieve an in-depth understanding of the nature of diversity within the institution and to facilitate a process through which members of the community can strategize inclusivity through a proactive and iterative approach. According to Wenger, McDermott and Snyder (2002) CoP is a "group of people who share a concern, a set of problems, or a passion about a topic, and who deepen their knowledge and expertise in this area by interacting on an ongoing basis" (p. 4). Central to their definition is the fact that these communities are autonomously regulated and their members share similar concerns to be solved using a variety of tools such as stories, prior knowledge, experiences, documents or other related forms in their interaction. Consequently, these communities are able to come together to test new ideas, find solutions and improve current practices for better outcomes (Saint-Onge \& Wallace, 2003). Therefore, in this study, we employed $\mathrm{CoP}$ as the theoretical lens and methodological tool to understand the strategies higher education practitioners have devised for their inclusive teaching and learning practices in response to diversity related challenges. The data was collected through a series of observations and reflective journals.

The study was guided by the following question: In CoP, what strategies have higher education practitioners devised for their inclusive teaching and learning practices in response to diversity related challenges.

\section{LITERATURE REVIEW}

\section{Diversity and Inclusion}

Shore (2013) aesthetically describes diversity as "the mosaic of people" printed with a variety of backgrounds, styles, perspectives, values and beliefs." Furthermore, Loden and Rosener (1991) differentiated on the basis of primary and secondary dimensions to define diversity. According to them attributes that exert primary influence on individuals' personality, identity and world views such as gender, ethnicity, race, sexual orientation, age and mental or physical abilities and characteristics are defined as primary dimensions. Secondary dimensions, however, are less discernible but can exert a significant influence to the primary dimensions of diversity. These include educational background, geographical 
location, religion, first language, family status, work style, work experience, organizational role and level, income and communication style.

Diversity in higher education brings along a number of benefits as well as poses compelling challenges. For example, heterogeneous work groups have a variety of perspectives, experiences and knowledge and this results in enhanced problem-solving skills (Terenzini et al., 2001), better creativity (Pascarella et al., 2001), active participation and positive academic growth (Kaur, Noman, \& Nordin, 2017). However, failing to manage diversity in an effective way may result in poor engagement (Plaut, Thomas, \& Goren, 2009), restrict participation (Trotman, 2005) and may lead to inequality and subsequently undermine the potential transfer of learning among students (Cohen, 1994). Therefore, the practice of inclusivity that embodies the principles of equity, equalization, and integration become fundamental in managing diversity.

Inclusion is viewed as a way of thinking, an orientation, an ideology or as a set of practices or even policies that foster human rights, respect for differences and value in diversity for just and democratic learning communities (Cushner, et al., 2009). Furthermore, Hockings (2010) described inclusivity as "the ways in which pedagogy, curricula and assessment are designed and delivered to engage students in learning that is meaningful, relevant and accessible to all. It embraces a view of the individual and individual differences as the source of diversity that can enrich the lives and learning of others." (p. 1). May and Bridger (2010), proposed four dimensions: institutional commitment, curriculum design and content, pedagogy and instructional delivery, and assessment to be considered for developing and implementing inclusive teaching and learning. Students' experiences of inclusion such as when they feel belonged and connected with others in a meaningful way result in enhanced academic, social and emotional adjustment at the university (Kift et al., 2010).

\section{Community of Practice (CoP)}

It is understood that the phenomenon of $\mathrm{CoP}$ is as old as mankind. In fact most of us knowingly or unknowingly have been participating in unnamed communities sharing our stories and experiences and 
learning from them. However, Lave and Wenger (1991) formally described $\mathrm{CoP}$ as a group of people, who share common interests and goals, coming together to share their stories and experiences to enhance knowledge or solve problems. Further Wenger et al. (2002), described CoP as "groups of people who share a concern, a set of problems, or a passion about a topic, and who deepen their knowledge and expertise in this area by interacting on an ongoing basis" (p 4).

The key features of CoP is that they are autonomous and selfregulatory in nature where people share their experiences, discuss issues, explore and test ideas, apply their skills which, in turn, builds new knowledge around their subject matter and provide insights for further improvement in their practices. In other words, "Community members develop common sets of codes and language, share norms and values, carry out critical reflection, and engage in dialogue with each other at a professional level, generating an environment characterized by high levels of trust, shared behavioural norms, and mutual respect and reciprocity" (Agrifoglio, 2015, p. 26). Wenger (1998) offered three dimensions: Joint enterprise, mutual engagement and shared repertoire as central to CoP. Joint enterprise refers to shared goals or the purpose of engagement. For example, in the context of the present study it refers to diversity and inclusion issues. Mutual engagement refers to the functioning of $\mathrm{CoP}$ where the norms and social interaction binds the community into a social entity. In the context of the present study mutual engagement is demonstrated through a series of meeting sessions described in the methodology section. Finally, shared repertoire refers to the resources and learning tools such as past experiences, artifacts, stories, knowledge that community members bring together to build new knowledge. For example, in this study, members of the institute contributed their experiences and insights in relation to their diversity and inclusion experiences, past and present.

The synthesis of literature suggests that CoPs can take place in varied forms (Agrifoglio, 2015). It can be categorized on the basis of age, size, life span, institutional level, boundaries, creation process, background of individuals and interaction medium. As per these guidelines, the CoP of the present study was created intentionally within an institution and considered small in size as it comprised only a few members from heterogeneous backgrounds who interacted face-to-face on a temporal basis until the research 
objectives were achieved. As mentioned, context is central to strategizing diversity initiatives. Therefore, individuals who are practitioners in a particular context can be brought together through $\mathrm{CoP}$ to share their experiences and insights to strategize inclusive teaching and learning practices.

\section{METHODOLOGY}

This study adopted a qualitative research paradigm to understand what strategies do higher education practitioners employ through $\mathrm{CoP}$ in devising their inclusive teaching and learning practices in response to diversity related challenges in their classrooms. Qualitative inquiry was deemed appropriate for in-depth exploration of the research question and understanding the culture of a particular setting from the insider's perspective (Patton, 2002).

\section{Sources of Data Collection}

The information was generated through multiple data sources in this study. The primary source of data collection was observation by the researchers during the CoP. The observation included gathering information from discussions, listening to participants' narratives and inputs from their peers. The CoP lasted for seven months whereby a series of discussions (altogether 14 sessions), and sharing of reflections took place and inputs from participants, peers or critical friends were also generated. All the sessions were audio and video taped and later transcribed verbatim. The second source of data was reflective writing submitted by the participants. The details on this source are elaborated in the data collection procedure.

\section{Participants and Settings}

The university, where the study was conducted, currently hosts students from 40 countries and 101_visiting academicians from more than 22 countries (CIAC-UUM, 2013). This significantly adds up to the pre-existing diversity of a multicultural society in Malaysia and is in line with the Malaysian Ministry of Higher Education's (MOHE, 2011) internationalization agenda.

Purposive sampling strategy was employed in selecting the participants as the study was seeking a platform to build a community 
of higher education practitioners who had experience in student diversity in higher education. As Patton (2002) stressed, purposive qualitative sampling is "choosing information-rich cases for indepth study when one wants to understand something about those cases without needing or desiring to generalize to all such cases" (p. 169). The participation was voluntary and the participants were assured anonymity.

Six (6) academicians who emerged from natural retention along the iterative cycles on $\mathrm{CoP}$ participation were considered as participants. From the initial pool of 18 registered participants in the first few sessions, nine participants attended initial sessions of phase two, while six participants persisted and participated fully within the community till the end. The diminishing attendance of the participants was viewed as a natural phenomenon due to the various options for professional development at the campus. It is likewise important to consider that building a community of practice grows initially on informal and unstructured ways (Lave \& Wenger, 1991). Therefore a prerequisite in this study was that only participants who opted voluntarily and went through the entire phase of the $\mathrm{CoP}$ were considered legitimate participants, and that none of them were coerced into the process. Table 1 provides information on the participants' details.

Table 1

Details of Participants

\begin{tabular}{lllccc}
\hline & $\begin{array}{l}\text { Country of } \\
\text { origin }\end{array}$ & Specialization & $\begin{array}{l}\text { Years of } \\
\text { teaching } \\
\text { experience }\end{array}$ & Gender & $\begin{array}{l}\text { Language } \\
\text { used }\end{array}$ \\
\hline 1 & $\begin{array}{l}\text { South Korea } \\
\text { (L) }\end{array}$ & Linguistics & 20 & $\mathrm{M}$ & English \\
2 & India (M) & $\begin{array}{l}\text { Educational } \\
\text { management }\end{array}$ & 22 & $\mathrm{M}$ & English \\
3 & Uganda (Y) & $\begin{array}{l}\text { Instructional } \\
\text { technology }\end{array}$ & 16 & $\mathrm{M}$ & English \\
\hline
\end{tabular}

(continued) 


\begin{tabular}{|c|c|c|c|c|c|}
\hline & $\begin{array}{l}\text { Country of } \\
\text { origin }\end{array}$ & Specialization & $\begin{array}{l}\text { Years of } \\
\text { teaching } \\
\text { experience }\end{array}$ & Gender & $\begin{array}{l}\text { Language } \\
\text { used }\end{array}$ \\
\hline 4 & Indonesia (A) & Philosophy & 15 & M & $\begin{array}{l}\text { English \& } \\
\text { Malay }\end{array}$ \\
\hline 5 & Nigeria (K) & $\begin{array}{l}\text { International } \\
\text { studies }\end{array}$ & 11 & M & English \\
\hline 6 & Indonesia $(\mathrm{H})$ & $\begin{array}{l}\text { Instructional } \\
\text { technology }\end{array}$ & 10 & M & $\begin{array}{l}\text { English \& } \\
\text { Malay }\end{array}$ \\
\hline 7 & Malaysia (R) & $\begin{array}{l}\text { Educational } \\
\text { psychology }\end{array}$ & 26 & $\mathrm{~F}$ & $\begin{array}{l}\text { English \& } \\
\text { Malay }\end{array}$ \\
\hline 8 & Philippines $(\mathrm{N})$ & $\begin{array}{l}\text { Development } \\
\text { studies }\end{array}$ & 31 & $\mathrm{~F}$ & English \\
\hline 9 & India $(\mathrm{X})$ & $\begin{array}{l}\text { Educational } \\
\text { psychology }\end{array}$ & 17 & $\mathrm{~F}$ & English \\
\hline
\end{tabular}

\section{Procedure}

Data collection spanned a three-phase cycle which corresponded to 11 face-to-face sessions during the first semester, and an additional three sessions in the following semester. The entire duration to a great extent, ensured context sensitivity (McMillan \& Schumacher, 2010) where data and narratives emerged in a reflective manner. The researchers who were themselves the mentors were able to structure the group to transit into a community of practice whereby discussions were facilitated in an informal manner. The following is a report which clearly details a total of 14 sessions in three phases that describes the functioning of the $\mathrm{CoP}$ and the process on how strategies are devised.

Phase 1: During the first phase, qualitative questions and probes were used to gather the participants' knowledge and perspectives about learner diversity and gradually delved deeper into the challenges recurring in their classes that underlie human variation and individual differences. Phase 1 viewed as a levelling and connecting transition provided the initial trigger for the participants to share their expectations and conceptions of teaching diverse students. The 
challenges they faced in class were shared through story-telling. During these sessions a free-flowing discussion was sustained to allow for participants' emergent perspectives and behaviour to naturally unfold in describing their experiences in student diversity.

Phase 2: In order to mobilize the community and provide direction to the participants to interface, the mentor provided the following sets of reflective questions to answer only once using Gibbs' (1988) reflective cycle. The reflective questions are as follows:

Question 1- What recurring issues and concerns did you encounter when teaching diverse classes at the university?

Question 2- What crucial feelings, assumptions, and course of action came naturally to you during these encounters?

Question 3- Where do you think this journey is taking you? Is there a better way to render equitable, effective learning among students of varied backgrounds and abilities? If so, describe.

Self-reflection is considered a powerful tool for academicians who seek continual professional development and are willing to enhance their teaching practices. Critically reflective academicians question and reflect on their andragogy and teaching goals. After writing down their thoughts and insights and sharing them with a pair and later with a large group, they became engaged in open discussion. Clarifying individual intentions occurred when the participants began to immerse themselves in the discussion. During this phase, reading materials and articles were distributed to the participants and they were encouraged to read and explore more relevant reading resources in order to discuss strategies that can yield desired outcomes to manage diversity in the classroom.

Support mechanisms, personal consultations, online interactions, and follow-up prompts from mentors were extended to all the participants to facilitate the process. Inter-group interactions and exchange of insights were also encouraged. The groups were already beginning to appear engaged and this evidently became the longest phase in the cycle. In the next three consecutive sessions, the participants carved their own strategies to resolve major challenges they encountered, discussed with the group and improved or edited their plan based on peer inputs. 
Phase 3: This was marked as the second longest and the most engaging phase. The participants had forged a relationship (mutual engagement) amongst themselves on their shared goal (joint enterprise) of devising appropriate strategies to counter diversity related challenges in their classes through their shared resources and tools (shared repertoire). Even though the community interacted in informal ways, the community mentor ensured that focus on the topic was maintained to increase outcome within a limited time. During this phase, individual oral presentations coupled with slides and print outs of post-reflection narratives facilitated the identification of factors and circumstances surrounding their perspectives and preferences for certain strategies. An atmosphere of continuous inquiry and cross-critiquing of reported practices was observed. Drawn from the same phase were the participants' voices of which the key constructs of diversity and motivation toward culturally responsive teaching were used as guideposts in organizing recurrent themes such as inclusive teaching/instructional practices.

\section{Data Analysis}

The data from observations (video/audio tape) and reflection questions were transcribed immediately after each session and subjected to the procedures of inductive analysis to generate categories. Data from all sources was compared to establish trustworthiness through triangulation (Merriam, 2009). The data was explored by reading and rereading at preliminary stages to obtain clarity (Denzin, 2005) and through repetitive readings the data was coded under two prime categories, namely: challenges and strategies. Later, based on prevalence and frequency counts (McMillan \& Schumacher, 2014) the strategies were analyzed against the challenges reported and finally the strategies were reduced to major themes. These themes were sent for member checking to secure reliability. Details of the findings are presented in the next chapter.

\section{Findings}

The present study adopted CoP as a theoretical and methodological lens in order to facilitate higher education practitioners from a public university, with a diverse student population to formulate their inclusive teaching and learning practices in response to the challenges they encountered. The findings highlighted diverse 
ways in which inclusivity was strategized in negotiating a variety of challenges encountered along the way. During the data reduction process, three major themes emerged which reported the inclusive strategies conceived by the participants. The following themes elaborate the findings supported by verbatim evidence. Alphabetical letters are used as codes to denote participant identity.

\section{Inclusive/differentiated Assessment}

Challenges related to creating fair and valid assessments of students with diverse attributes were abundantly indicated in the analysis. Conversations during the sessions revealed that the participants' prime and prevalent challenge pertained to the students' varied English language abilities. This was because the demographic composition in most classes consisted of several local students who were not exposed to international education and foreign students who were mainly from non-native English speaking countries. Therefore, in most classes some students were proficient; some had working language proficiency while others had limited English language proficiency which taken together posed a huge challenge for the lecturers to design appropriate assessments. The participants' experience when sharing during the initial phase, suggested that delivering instructions to students of varying English language abilities was fairly manageable. For example, K suggested "we use multiple modes to disseminate information and create heterogeneous groups by putting students of varying English language proficiency levels together to collaborate and learn together." Similarly, A stated upon reflection that "most of the time students go back to read and research in their preferred language." However, the primary concern regarding this challenge remained concentrated on assessment. As $\mathrm{M}$ put it in his struggles, "in our classes linguistic diversity is the biggest challenge...60\% of students preferred to write exam in Malay while others preferred writing in English." Furthermore, the need for inclusive and differentiated assessment was raised when the participants, during their interactions, highlighted that there were variations in the skills and knowledge of students. For example, $\mathrm{H}$ said, "Some of my students are slow and some are fast learners. Some students got the concept very fast, some are participative and confident and some lack skill or confidence." Similarly X said, "My students as part-time postgraduate students bring in a variety of skills and experiences; for them, they may not be good in the subject 
matter but they have several other skills to contribute." Therefore, it was agreed in the community that creating differentiated assessments, assessments that were inclusive in nature and provided equal opportunity for all students to participate, could be valuable. $\mathrm{K}$ mentioned in his reflection that he did not make judgements on the basis of a single type of assessment, "he provides individual assessments as well as group assessments and gives autonomy to students to submit their assignments in a variety of forms." The participants collectively agreed on allowing flexibility in terms of preferred language and mode to give equitable opportunity to all students. For example, A described in his reflections, "we can try to work in small groups, maintain balance and do intense observation. In my case I make sure each student presents one topic, each student has to write on a topic of their choice and in their preferred language and own experience." Differentiation in assessment was further elaborated when the participants discussed the possibility of incorporating peer and self-assessment as a way to address diversity. According to the participants, peers can function as critical friends as well as collaborate in areas of their expertise. $\mathrm{N}$ shared a class incident,

In my initial assessment I found some students were either hesitant, they were not able to present, after discussion I found that they wanted to present in their own language. I thought why not let them present in their own mother tongue and ask peers to give feedback. I also found that students were able to mark each other successfully.

L also openly agreed to language flexibility in assessment through peer involvement, when she related her experience,

"Sometime it's ok if they present in BM (Malay language) you can assess the substance, confidence seeing their body language, delivery style and expression of audience. In my classes, peers are involved in assessing. I give them opportunities to share and give feedback to each other."

This way, participants thought, not only their self-efficacy is supported but they feel competent and determined in their learning experiences. 


\section{Motivation and Goal Strategies}

Data revealed that while the participants discussed and shared their experiences on students' diversity, variations in students' conation were significantly highlighted. Each participant had students who had different motivational levels when participating and learning in the classroom. This diversity became a challenge for some lecturers as indicated by $\mathrm{R}$ :

In my class there is a mix of students for motivation and engagement level. Normally the class seating arrangement tells a lot about students' motivation and engagement, as bright and engaging students like to sit in front.

$\mathrm{L}$ also shared his experiences on motivation based differences in his class which he wished to overcome in order to secure a relatively, well-distributed student participation. He said, 'This term I have some students who are active and participative but others are reticent and non-responsive. My dilemma is how can I help the other half to improve. I want to give special time." $\mathrm{K}$ also described experiences in his reflection that highlighted differences in student learning intention, motivation, and engagement. He said, "In general we have two types of students, who are diligent and understand the purpose of school...others come for a degree only. And they are not motivated." Besides individual differences, the differences that affected students' profile were attributed to cultural differences. For example, Y said, 'My students are submissive and quiet. As a political studies lecturer, I feel power distance is prevalent among students. They are hesitant to talk and don't discuss matters openly." During the discussions, the participants collectively agreed that most students preferred structure and order with clear rules and guidelines and avoided challenges and uncertainties. $M$ experienced this while trying to introduce a change in his assessment methods in class. He recalled in the interview-

There was a mutiny in the classroom. Nobody was able to understand what I was trying to change. They were not ready to take it and made excuses...like they some of them said they didn't have Whatsapp or smart phones. The issue was when we bring in something new there is a resistance. 
The interaction revealed that students' goals for learning were more achievement oriented rather than mastery of learning. For example, A described upon reflection, "Students are exam-oriented, their class attendance focuses too much on taking exams. They are anxious of exams and they always want to know more about exam details and guidelines."

Discussions on these issues lead the participants to agree that motivational strategies need to be aligned with students' profile and their backgrounds. It was agreed that students' voices must be heard; they must be invited to contribute their perspectives on teaching and learning. For example, $\mathrm{X}$ remarked that, "If we plan teaching such as researching for teaching resources, planning instruction in collaboration with students, they demonstrate genuine interest and stay motivated." Likewise, to increase motivation and engagements, it was agreed that students must be provided a rationale for their learning. For example, L shared his experiences and outcomes, he said,

I seek their opinion and give them chance to take part in decision-making such as what dates do they suggest for assignment submission, for quizzes, I try to connect old topics with new ones to establish connectivity, relevance and interest. Overall before any activity or assessment, I explain the reason for doing it.

Teachers must create class structures that are more focused on mastery of learning rather than performance by highlighting the relevance and importance of the course. To overcome the issue of power-distance which also prohibits student participation at a required level and creates motivation deficit, a suggested strategy is to treat students as partners in learning and create a rapport with them to bridge the learning gap. For example, L mentioned a friendly strategy that "he usually crack jokes and try to socialise with them to make students to feel close and friendly." Similarly, N mentioned that calling students by their names create a personal bond with them, students experience belongingness, they feel connected and ultimately, motivated. He said:

I try to memorise their names. It is challenging. If names are too big I use nick names. 
I give a variety of incentives for them to share and participate to accept challenges.

\section{Inclusive Pedagogy}

As highlighted in the previous themes, variations in English language proficiency, individual differences in motivation and culture were the central issues which needed to be addressed. However, institutional challenges were also highlighted in the $\mathrm{CoP}$ which posed a barrier in addressing diversity among students. For example A said:

Sometimes class size becomes an issue, too big class can be 150 and too small can be 36. I tried to work in small groups, maintain balance and do intense observation...I ask questions directly to students to ensure learning.

Therefore, there was considerable discussion in the CoP on modifying teaching practices and incorporating variety in delivery modes. Some of the potential ways to overcome these challenges were through relying on technology to conduct classes, share information and impart instruction. For example, $\mathrm{K}$ wrote “... encourage students to share their work by uploading power point slides and other documents in the learning zone." He also believed that social media is a powerful platform for informal learning; therefore, he used them extensively. Likewise R said,

There is a need for informal learning opportunity, since students enjoy using Twitter and Facebook. I think Twitter and Facebook can be resourceful for me in teaching and learning process. There are several advantages to social media...it promotes learning outside the classroom and students feel free to share.

Cultural differences highlighted in the discussion were also a reason for adopting diversity in pedagogy. Participants expressed that they had to struggle in finding culturally appropriate contents for teaching different cultural groups. $\mathrm{H}$ explained:

Sometimes the movies that I choose don't work because of the eastern and western differences. The students are 
from the east and movies from the west. Then there is a cultural gap in using western material with eastern students to teach.

According to him, students were able to better identify with the contents that connected them with their culture. He added that, "Students are able to make better sense of the content when presented in their own cultural context. The text contents are sometimes challenging in western philosophy. Eastern audience and religions are so varied. It is challenging to handle the criticism from that material." Therefore, it was agreed that when imparting instructions, the instructors must remain sensitive to the cultural needs of students and acknowledge their world views. For example, Y said "I formed groups across race, religions and nationalities. It helped and enabled students think across cultural, broaden their perspective and work as teams." H said, "every student prefers stories from their own traditions so I use culture appropriate material, Therefore, my choice of stories, and other material ranged e.g. for Tamil (Ramayana ) to Chinese (Dinash, Ming) and Malay (Hang Tuah)."

$\mathrm{K}$ shared his experience about the religious conflict that once occurred in his class. He "balanced the argument and encouraged respect and sensitivity in open debate and discussion" for topics that could be culturally or religiously sensitive to extend intercultural support.

The discussion related to challenges owing to diversity in cultures was in integrating or bringing students of different cultures together to work or learn. Students of similar cultures preferred to stick together with their friends thereby creating a cultural divide in the classroom. Another visiting scholar, Y revealed his concern:

Students are racially sensitive and prefer to work with their same race group. I can also see this ethnic divide in the class in form of seating arrangement. Chinese, Indians and Malays, Arabs stick to their groups and these groups sit in different places.

Therefore, it was agreed that by incorporating a collaborative learning environment, the lecturers could encourage learners to interact in multiple and meaningful ways, develop critical, communication and 
social skills (Rahman et. al., 2016). It was regarded as a beneficial strategy for a diverse class where opportunities for interaction, discussions and debates between students could help bring them together and pave the way to resolve differences. For example, $\mathrm{H}$ mentioned in his reflections about "peer and group activity based on scenario study" where groups of students can come together to solve an academic problem. Similarly, A also shared his experience of using "peer-to-peer discussions" that encouraged students to come together and discuss. Y also supported this strategy saying that "for better learning and cognition I put students in pairs, just provide material and give them time to explore within themselves." Even $\mathrm{N}$ feels a compelling need to use collaborative learning as a means to handle diversity. He said, "They are not independent learners; they learn to work in groups; they can be very smart and creative if we create the right environment for them. It's our challenge to unlock their potential."

\section{Discussion and Conclusion}

In order to understand and strategize inclusivity, it is necessary to understand local conceptualization of inclusion related issues and challenges. For example, the USA based diversity and inclusion studies, along with the other issues, placed higher emphasis on race relations between blacks and whites (Mitchell et al., 2006; Douglas, 2011; Richard \& Packard, 2012), whereas, the findings of the present study demonstrated that in spite of Malaysia being a multi-racial society, it did not emphasize race relations as a major concern for designing inclusion. The recurring challenges related to diversity discussed in the $\mathrm{CoP}$ were mainly focused on individual differences in terms of cognition, skills and conation, linguistic and cultural diversity. A few institutional policies were also among the issues to be addressed through inclusion.

Language is considered as an essential tool that is used for communication and interaction in the teaching and learning process. Therefore, students' inefficiency in the primary language of the classroom may pose a huge challenge in the process of teaching and learning for both the students and the teacher (Chamberlain, 2005). However, it would be unfair to utilize assessment methods that are exceedingly dependent on the English language proficiency only. During the discussions and on the basis of the past experiences of 
other lecturers, it was concluded that alternative forms of assessment could provide equal opportunities for all students to demonstrate their learning.

Modification and accommodation were suggested as two essential dimensions to support alternative assessments for diverse learners (Noman \& Kaur, 2014; Kaur, Noman, \& Awang-Hashim, 2018). Modifications refer to adapting standards of expected outcomes for students who need help and assess them on the basis of their current level. Accommodation refers to allowing for demonstration of learning using a method that is preferred by the students. This strategy was found to be equally effective to handle challenges related to variations in skills. For example, a student who may not be confident in his language and presentation skills can contribute meaningfully in more constructive ways by integrating technology or bringing critical insights for contents to be shared. The literature suggests that content comprehension in one's preferred language not only promotes engagement but also enhances cognition and academic achievement (Ball 2010; Kaur, et al., 2017). The second theme suggests that in the present context, inclusive strategies require careful consideration for motivation and goal strategies since the practitioners struggled with variations in students' goals and motivation to learn. The sources of these variations were found to be embedded in the students' goals and cultural inclination. For example, $\mathrm{M}$ said, there were students who came to the class to merely get grades to achieve degrees. On the other hand, there were some who genuinely wanted to master the knowledge. Students' cultural orientations such as power-distance and uncertainty avoidance (Hofstead, 2011) significantly affect their motivational orientations. In order to address these challenges, the CoP agreed to establish student faculty partnerships (Cook-Sather, Bovill, \& Felten, 2014) whereby, the students would be invited to contribute their voice in instructional design, assessment and curriculum planning. This would not only promote their engagement but would enhance their competence. Besides, it was proposed that in motivating students to undertake a task that may be difficult or uninteresting to perform, the lecturers could provide a clear rationale how the learning could be beneficial to them (Reeve, 2006).

It was also understood that providing autonomy in classroom instruction such as presenting students with options, listening to 
their perspectives to design instruction and assessment will enhance student accountability and facilitate volition (Deci \& Ryan, 2008). Furthermore, creating a bond with the students whereby teachers remain aware of students' needs, provide support for their needs and work closely with them would not only facilitate strong relatedness but also undermine traditional notions of power assertion by teachers (Vansteenkiste, et al., 2006). The third theme suggests a range of strategies that could be embraced and delivered directly through the instructional plan to address cultural differences among students, to provide equal opportunities to students with diverse skills and English language proficiency. For example, the use of technology in a variety of media to teach, to disseminate information and to offer students a platform whereby they can interact in preferred ways and also use various means to demonstrate their knowledge (McGhieRichmond \& de Bruin, 2015). Another recommended strategy is to encourage students to work on collaborative projects where there is opportunity to interact, solve problems together while listening to each other's perspectives. Such collaborative projects improve students' engagement, critical thinking, negotiation, communication and team skills and at the same time provide students with the choice to work in their preferred area of interest, skills and language (Tomlinson \& Imbeau, 2011). Overall, the framework of inclusive practices which emerged from the present findings suggests a close proximity with universal design for learning (UDL) advocated by Rose, Gravel, and Gordon (2014). UDL was founded on three principles: (a) multiple means of engagement, (b) multiple means of representation, and (c) multiple means of action and expression. The central principle of these strategies, like the findings also suggest that instruction, assessment and motivation styles can be adapted to accommodate and suit the preferences of diverse learners.

Finally, this study was aimed at exploring inclusive practices of higher education practitioners in response to the challenges they faced within their institution through a CoP. This study highlighted the significance of CoP as a professional development tool. The higher education institutes should encourage the nurturing of such professional development networks whereby individuals can come together and share insights on common issues and construct new and diverse perceptions. Ultimately, this research has contributed to a greater understanding of the processes involved in developing 
and embedding inclusion within instructional practices in higher education. It is hoped that the findings of this work will act as a framework to manage diverse learners to meet their broad-based needs in higher education in this context and elsewhere. Besides, inviting diverse student bodies to participate in discussion sessions using similar platforms could contribute insightful strategies.

\section{ACKNOWLEDGEMENT}

This study was supported by Scholarship of Teaching And Learning Research Grant [SO Code 13013] by the University teaching and Learning center (UTLC),Universiti Utara Malaysia, Malaysia.

\section{REFERENCES}

Agrifoglio, R. (2015). Communities of Practice. In Knowledge Preservation through Community of Practice (pp. 25-46). Springer Briefs in Information Systems. Springer, Cham Doi: 10.1007/978-3-319-22234-9_2.

Ainscow, M. (1999). Understanding the development of inclusive schools. London: Routledge.

Ary, D., Jacobs, L. C., Razavieh, A., \& Sorenson, C. K. (2009). Introduction to Research in Education (8th ed.). Belmont, CA: Wadsworth.

Barrington, E. (2004). Teaching to student diversity in higher education: How multiple intelligence theory can help. Teaching in Higher Education, 9(4), 421-434.

Ball, J. (2010). Enhancing learning of children from diverse language backgrounds: Mother tongue-based bilingual or multilingual education in the early years. UNESCO. Retrieved from http:// unesdoc.unesco.org/images/0018/001869/186961e.pdf.

Chamberlain, S. P. (2005). Recognizing and responding to cultural differences in the education of culturally and linguistically diverse learners. Intervention in School and Clinic, 40, 195211.

CIAC (2013). The Centre for International Affairs and Cooperation. Universiti Utara Malaysia.

Cohen, E. G. (1994). Designing group work: Strategies for the heterogeneous classroom (2nd ed.). New York: Teachers College Press. 
Cook-Sather, A., Bovill, C., \& Felten, P. (2014). Engaging students as partners in learning and teaching: A guide for faculty. San Francisco: Jossey-Bass.

Cushner, K., McClelland, A. \& Safford, P. (2009). Human diversity in education. Boston, USA: McGraw Hill, Inc.

Deci, E. L., \& Ryan, R. M. (2008). Self-determination theory: A macro theory of human motivation, development and health. Canadian Psychology, 49, 182-185.

De Wit, H. (2011). Trends, issues and challenges in internationalisation of higher education. Amsterdam, Netherlands: Centre for Applied Research on Economics and Management, Hogeschool van Amsterdam.

Denzin, N. K., \& Lincoln, Y. S. (Eds.). (2005). The handbook of qualitative research (3rd ed.). Thousand Oaks, CA: Sage.

Douglas, H., Winchester, D., Edgell, P. \& Gerteis. J. (2011). How Americans understand racial and religious differences: A test of parallel items from a national survey. The Sociological Quarterly, 52(3), 323-45.

Gale, T., \& Mills, C. (2013). Creating spaces in higher education for marginalised Australians: Principles for socially inclusive pedagogies. Enhancing Learning in the Social Sciences, 5(2), $7-19$.

Gibbs, G. (1988). Learning by doing: A guide to teaching and learning methods. Oxford: Further Education Unit, Oxford Brookes University.

Hofstede, G. (2011). Dimensionalizing cultures: The hofstede model in context. Online Readings in Psychology and Culture, 2(1). https://doi.org/10.9707/2307-0919.101.4

Hockings, C. (2010). Inclusive learning and teaching in higher education: A synthesis of research evidence. York: Higher Education Academy.

Kaur, A., Noman, M., \& Awang-Hashim, R. (2018). Exploring and evaluating differentiated assessment practices of inservice teachers for components of differentiation. Teaching Education, Doi: 10.1080/10476210.2018.1455084

Kaur, A., Awang-Hashim, R, \& Noman, M. (2017). Defining Intercultural Education in Malaysian Context for Social Cohesion. International Journal of Multicultural Education, 19(2), 44-60.

Kaur, A., Noman, M., \& Nordin, H., (2017). Inclusive assessment for linguistically diverse learners in higher education. Assessment \& Evaluation in Higher Education, 42(5), 756-771. 
Kift, S., Nelson, K., \& Clarke, J. (2010). Transition pedagogy: A third generation approach to FYE - A case study of policy and practice for the higher education sector. The International Journal of the First Year in Higher Education, 1(1), 1-20.

Lave, J., \& Wenger, E. (1991). Situated learning: Legitimate peripheral participation. Cambridge: Cambridge University Press.

Loden, M., \& Rosener, J. B. (1991). Workforce America! Managing employee diversity as a vital resource. Illinois: Business One Irwin.

McGhie-Richmond, D., \& de Bruin, C. (2015). Tablets, tweets and talking text: The role of technology in inclusive pedagogy. In J. M. Deppeler, T. Loreman, and R.A. L. Smith (Eds.). Inclusive pedagogy across the curriculum: International perspectives on inclusive education, Volume 7, (pp. 211-234). Bingley, UK: Emerald Group Publishing.

McMillan, J. H., \& Schumacher, S. (2014). Research in education evidence based inquiry. London-Pearsons.

May, H. \& Bridger, K. (2010). Developing and embedding inclusive policy and practice in higher education. York: The Higher Education Academy.

Merriam, S. (2009). Qualitative research: A guide to design and implementation. San Francisco, CA: Jossey-Bass.

Mitchell, C., Denson, N., Saenz, V., \& Misa, K. (2006). The educational benefits of sustaining cross-racial interaction among undergraduates. Journal of Higher Education, 77(3):430-55.

Ministry of Higher Education. (2011). Internalization thrusts in Malaysia, Putrajaya, Malaysia.

Noman. M, \& Kaur, A. (2014). Differentiated assessment: A new paradigm in assessment practices for diverse learners. International Journal of Education and Applied Science, 1(4), 167-174.

Plaut, V. C., K. M. Thomas, \& M. J. Goren (2009). Is multiculturalism or color blindness better for minorities? Psychological Science, 20, 444-446.

Patton, M. Q. (2002). Qualitative research \& evaluation methods (3rd ed.). Thousand Oaks, CA: Sage.

Rahman, N. A., Masuwai, A. Tajudin, N. M., Tek, O. E., \& Adnan, M. (2016). Validation of teaching and learning 
guiding principles instrument for Malaysian Higher Learning institutions. Malaysian Journal of Learning and Instruction, 13(2), 125-146.

Richard, P., \& Packard, J. (2012). Activating diversity: Examining the impact of student race on contributions to course discussions. The Sociological Quarterly, 53(2), 295-320.

Saint-Onge, H., \& Wallace, D. (2003). Leveraging communities of practice for strategic advantage. Burlington, MA: Butterworth-Heinemann.

Schneider, C. G. (2000). Diversity requirements. Liberal Education, $86,2-3$.

Shore, L. M. (2013). Diversity and inclusion in organization: The challenge and opportunity for higher education. Presentation at the University of Lausanne, Diversity conference, May 28, 2013.

Rose, D. H., Gravel, J. W., \& Gordon, D. (2014). Universal design for learning. In L. Florian (Ed.), Sage handbook of special education (2nd ed., pp. 475-491). London: SAGE.

Reeve, J. (2006). Teachers as facilitators: What autonomy-supportive teachers do and why their students benefit. Elementary School Journal, 106, 225-236.

Terenzini, P. T., A. F. Cabrera, C. L. Colbeck, S. A. Bjorklund, and J. M. Parente. (2001). "Racial and Ethnic Diversity in the Classroom: Does It Promote Student Learning?" The Journal of Higher Education, 72(5), 509-529.

Tomlinson, C. A., \& Imbeau, M. (2011). Managing a differentiated classroom: A practical guide. New York, NY: Scholastics.

Trotman, C. (2005). From the margins to the mainstream: Embedding widening participation in higher education. London: Universities UK.

Vansteenkiste, M., Lens, W., Soenens, B., \& Luyckx, K. (2006). Autonomy and relatedness among Chinese sojourners and applicants: Conflictual or independent predictors of wellbeing and adjustment? Motivation and Emotion, 30, 273-282.

Wenger, E. (1998). Communities of practice: Learning, meaning, and identity. Cambridge University Press.

Wenger, E., McDermott, R., \& Snyder, W. M. (2002). Cultivating communities of practice (1st ed.). Watertown, MA: Harvard Business School Press. 